\title{
Synovial Cell
}

National Cancer Institute

\section{Source}

National Cancer Institute. Synovial Cell. NCI Thesaurus. Code C13059.

A fibroblast that lies between the cartilaginous fibers in the synovial membrane of joints. 